\title{
The Ability to Pay for Long-Term Care in the Netherlands: A Life-cycle Perspective
}

\author{
Arjen Hussem ${ }^{1}$ - Casper van Ewijk ${ }^{2}$. \\ Harry ter Rele ${ }^{3}$ - Albert Wong ${ }^{4}$
}

(C) The Author(s) 2016. This article is published with open access at Springerlink.com

\begin{abstract}
This paper uses synthetic life-cycle paths at the individual level to analyze the distribution of long-term care expenditures in the Netherlands. Using a comprehensive set of administrative data 20,000 synthetic life-cycle paths of household income and long-term care costs are constructed using the nearest neighbor resampling method. We show that the distribution of these costs is less skewed when measured over the life-cycle than on a cross-sectional basis. This may provide an argument for self-insurance by smoothing these costs over the life-cycle. Yet costs are concentrated at older ages, which limits the scope for self-insurance. Furthermore, the paper investigates the relation between long-term care expenditures, household composition, and
\end{abstract}

The authors thank Niels Kortleve, Bert Smid, Daniel van Vuuren and Bram Wouterse for their valuable comments.

$\bowtie \quad$ Arjen Hussem

arjen.hussem@pggm.nl

Casper van Ewijk

c.vanewijk@uva.nl

Harry ter Rele

h.j.m.ter.rele@cpb.nl

Albert Wong

albert.wong@rivm.nl

1 PGGM, P.O. Box 117, 3700 AC Zeist, The Netherlands

2 University of Amsterdam, Amsterdam, The Netherlands

3 CPB Netherlands Bureau of Economic Policy Analysis, The Hague, The Netherlands

4 Department of Statistics, Informatics and Mathematical Modelling, National Institute for Public Health and the Environment, Bilthoven, The Netherlands 
income over the life-cycle. The expenditures on a lifetime basis from the age of 65 are higher for low income households, and (single) women.

Keywords Life-cycle $\cdot$ Long-term care costs - Nearest neighbor resampling method $\cdot$ Self-insurance

JEL Classification $\mathrm{C} 33 \cdot \mathrm{D} 12 \cdot \mathrm{H} 53 \cdot \mathrm{I} 13$

\section{Introduction}

With $4.1 \%$ of GDP in 2013 Dutch long-term care (LTC) features the highest level of public costs within the European Union, well above the average level of $1.6 \%$ for all member states (European Commission 2015). In the absence of reform these care expenditures are projected to increase with another $4 \%$ points to over $8 \%$ of GDP in 2060 (European Commission 2015). The European Commission considers the rise in LTC expenditures as the main threat of sustainability of public finances for the Netherlands in the long run. The urgency for reform has been acknowledged by the current government which decided to decentralization of extramural long-term care to the municipalities. In the long run cost savings of $1.3 \%$ of GDP are expected to materialize in 2060. Even then total expenditure will rise to over $7 \%$ of GDP by 2060 which is still by far the highest of all EU countries, alongside Norway (European Commission 2015).

While the case of the Netherlands stands out, a rise in long-term care expenditures is anticipated for most Western countries (Francesca et al. 2011). These countries have in common that ageing populations will lead to an increasing prevalence of disability (e.g. De Meijer et al. 2011, 2012), and consequently, an increasing need for LTC. Given that these countries also often employ a pay-as-you-go financing scheme for LTC, there are many concerns on the sustainability of such schemes going forward.

Countries are hesitant to resort to private insurance to finance LTC spending. Francesca et al. (2011) show that the part of LTC spending financed by private insurance is relatively small in OECD countries (below $2 \%$ of total LTC; for the Netherlands even less than $0.5 \%$ ). The underdevelopment of private markets may point to myopia of consumers, and market failures such as adverse selection.

Yet, the threat of increasing LTC costs together with inefficiencies due to moral hazard is a good reason to consider methods of financing that rely more on private saving. Most of the more daily costs for LTC are limited in size, as they involve relatively small tasks that are performed at home (e.g. washing clothes, helping the client bathe, and so on). Moreover, the preference for ordinary consumption may fall if health deteriorates, so that there is scope for financing care expenditures out of current income (Finkelstein et al. 2013). Furthermore, if bigger LTC costs can be smoothed over the life-cycle this would enlarge the scope for self-insurance, also mitigating problems of moral hazard. This idea of self-insurance is similar to the life-cycle approach for social security (e.g. Bovenberg et al. 2012).

In this paper we develop a life-cycle perspective on LTC expenditures. Using a comprehensive set of administrative data we construct 20,000 synthetic life-cycle 
paths at the individual level which are representative for the Netherlands. We use the non-parametric nearest neighbor resampling approach (NNRA) (e.g. Farmer and Sidorowich 1987; Hsieh 1991) applied earlier by Wong et al. (2015) on health care, and now is extended to include LTC costs, income and family composition.

Taking a life-cycle perspective is essential for studying LTC for several reasons. To begin with, life-cycle paths provide information about the expectation and variation in LTC costs of individuals over the whole lifetime. This is important for analyzing the redistributive effects (of the financing) of LTC. Data on LTC and income over the full course of a life-cycle also allows us to assess the scope for smoothing shocks over the life-cycle by spreading costs over more years, 'self-insurance'. Including household composition is in particular relevant as mutual insurance within the household is a predominant factor in the context of LTC (Francesca et al. 2011). Bakx and De Meijer (2013) show that the availability of informal care at home is a key determinant of use of public LTC; people living alone have a much higher probability of recurring to public care. Other important determinants of LTC use are having a child, age, disability and health status (Bakx et al. 2013; De Meijer et al. 2011; Koopmanschap et al. 2011).

To our knowledge, there are no other studies that have combined a comprehensive life-cycle and a household perspective at the micro level to analyze the incidence of LTC costs. Some studies analyze lifetime costs of LTC, like Wouterse et al. (2013) and De Meijer et al. (2012), but they only look at the average cost for the individual. They do not relate lifetime costs to household composition, nor consider the dispersion in LTC-expenditures across individuals. In contrast, other studies take account of household composition when analyzing LTC, but neglect the life-cycle perspective. McClellan and Skinner (2006) and Bhattacharya and Lakdawalla (2006) look at the impact of household composition on medicare expenditures. Nihtilä and Martikainen (2007, 2008a, b) use Finnish panel data over a long period to study health, household income and other socio-economic determinants of long-term institutional care, but they also do not go into the lifetime distribution. Furthermore, there are differences in methodology. There is a broad literature on the determinants of LTC which is generally based on cross section data or macro data. Some micro simulation studies come closer to our approach (e.g. French and Jones 2004; De Nardi et al. 2009; Halliday 2011; Wouterse et al. 2013); our method, however, relies on synthetic lifecycles, and thus avoids estimating or calibrating parametric transition probabilities.

The life-cycle perspective is useful for analyzing the distribution of LTC costs over the various stages of the life-cycle. Furthermore, the association between life-cycle LTC costs and life-cycle income provides insight into the distributional effects of long-term care. Finally, from the 20,000 heterogeneous life-cycles we can analyze idiosyncratic risks in long-term care expenditures. This is relevant for assessing the need for insurance at different stages of the life-cycle. Murtaugh et al. (2001), Ameriks et al. (2011) and Brown and Warshawsky (2013) have established substantial potential welfare gains of LTC insurance in the US.

This paper is structured as follows. In the next section we describe the data and explain the synthetic life-cycle methodology. Section 3 considers the distribution of LTC expenditures over the life-cycle and across households. Section 4 analyses the relation between LTC costs and income, and develops a measure for the ability to 
pay for LTC. Finally, Sect. 5 concludes and discusses some possibilities for further research.

\section{Data and Methodology}

The Netherlands has a long tradition of institutionalized long-term care for elderly. For example, compared to Germany - which has a similar overall LTC utilization rate - the use of formal care is more prevalent in the Netherlands, while informal care is more important in Germany (Bakx et al. 2015). Long-term care insurance in the Netherlands is mainly provided by the government. All citizens participate in the insurance for LTC costs. Out of pocket expenses are small when compared to other countries. During our observation period 2004-2006 ${ }^{1}$ public long term care was completely covered by the Exceptional Medical Expenses Act (“AWBZ”). Each citizen pays an income related contribution, in 2006 amounting to $12.55 \%$ of income up to a maximum income of approximately 30,000 euro, and a substantial tax credit is in place. A government's agency decides about the applicant's eligibility based on two criteria: the individual's need and the availability of informal care. In addition to this regulated access, LTC use is also restrained by income related co-payments. These co-payments cover about $10 \%$ of total LTC costs. ${ }^{2}$

In this paper we use administrative micro data on LTC use and expenditures from the Administrative Office Exceptional Medical Expenses (Centraal Administratiekantoor-CAK), and mortality from the Death Causes Registry for the entire Dutch population, and administrative data and survey data on all income sources from Statistics Netherlands (Regionaal Inkomensonderzoek-RIO), and marital status from Statistics Netherlands (Gehuwdheidsbestand VRLHUWELIJKSGESCHIEDENISBUS). All this micro data has been made available by Statistics Netherlands). It covers the period from 2004 to 2006 which is representative for the period up to recent reforms. They include many of the important variables as age, gender, household composition and household income. Education level, health status and disability are not available. For further details, see Appendix 1.

Using these data, life-cycles are generated at the individual level by the method of nearest neighbor resampling on individual panel data from Statistics Netherlands. In essence, the method of nearest neighbor resampling builds an individual's life-cycle life year by life year, by sampling the above mentioned variables from individuals that have similar characteristics in a given life year (hence the "nearest neighbor"). Note that income and household type need not be constant over the life-cycle, but may change due to idiosyncratic shocks. The life-cycles obtained are pertinent to the system of long-term care present in the period 2004-2006, well before recent reforms. This period was chosen because of data availability, and also as this was a fairly stable period for the LTC system. There were no major breaks within this period. This is important as we want to exclude time effects in the way the synthetic life-cycles were constructed (De Meijer et al. 2015).

\footnotetext{
1 Recent reforms are not taken into account.

2 See e.g. Bakx et al. (2015) or Bakx and De Meijer (2013) for further reading on the Dutch LTC system.
} 
Table 1 presents some descriptives of the underlying data set. The data cover all households in the Netherlands. It distinguishes five household types. LTC expenditures are concentrated at the institutionalized; total expenditures for this small group covers about $50 \%$ of total expenditures on LTC. Being an LTC user in this table is defined as having strictly positive LTC costs.

\subsection{Income Concept}

We distinguish three income concepts: personal income (net income ${ }^{3}$ earned by the male or female), household income (net income earned by all the members in the household) and standardized income (see also Table 1). The latter is a measure of the standard of living of the individual members of the household and is calculated by dividing household income by the equivalence factor. The equivalence factor $(\geq 1)$ is meant to take account of the size of the household and economies of scale within the household (Siermann et al. 2004). Unless stated otherwise we use standardized income as the relevant measure for the ability to pay for long-term care. Because of risk sharing within the household we expect that LTC costs are borne by all household members (e.g. spouse). Additionally, standardized income is more relevant as an indicator for social economic status, which is known to be a good predictor of life expectancy (see e.g. Bonenkamp et al. 2013; Mackenbach et al. 1997; see Shkolnikov et al. 2011; Steingrímsdóttir et al. 2012 for the development of these socio economic differences) and health and LTC use (see e.g. Stronks et al. 1997; Lubitz et al. 2003 and De Nardi et al. 2015). Therefore, unless stated otherwise, income will be interpreted as standardized income.

Figure 1 gives the evolution of each of the income concepts at ages higher than 65 for males and females. Obviously, personal incomes are lower than household income. Furthermore, the standardized income is lower than total household income as it means to represent available income per person. For women standardized income is substantially higher than personal income; for men it is less as their partners on average have lower incomes; still it is higher than their personal income on average because of the economies of scale as measured by the equivalence factor. On balance, gender differences become much smaller when analyzing standardized incomes rather than personal incomes.

\subsection{Nearest Neighbor Resampling Method}

Because lifetime data on income and LTC use are not available we use the "nearest neighbor resampling approach" (NNRA) to simulate such data. Wong et al. (2015) applied this method on Dutch administrative panel data to jointly estimate acute health care expenditures and survival on an individual level, and thus obtain synthetic lifecycles of acute health care expenditures. The method has also been used in other

3 Defined as (disposable) personal income: income from labor, running one's own business, personal capital, benefits and received transfers minus paid income transfers, contributions paid by employers, health care contributions and tax on income and personal capital (Statistics Netherlands). 


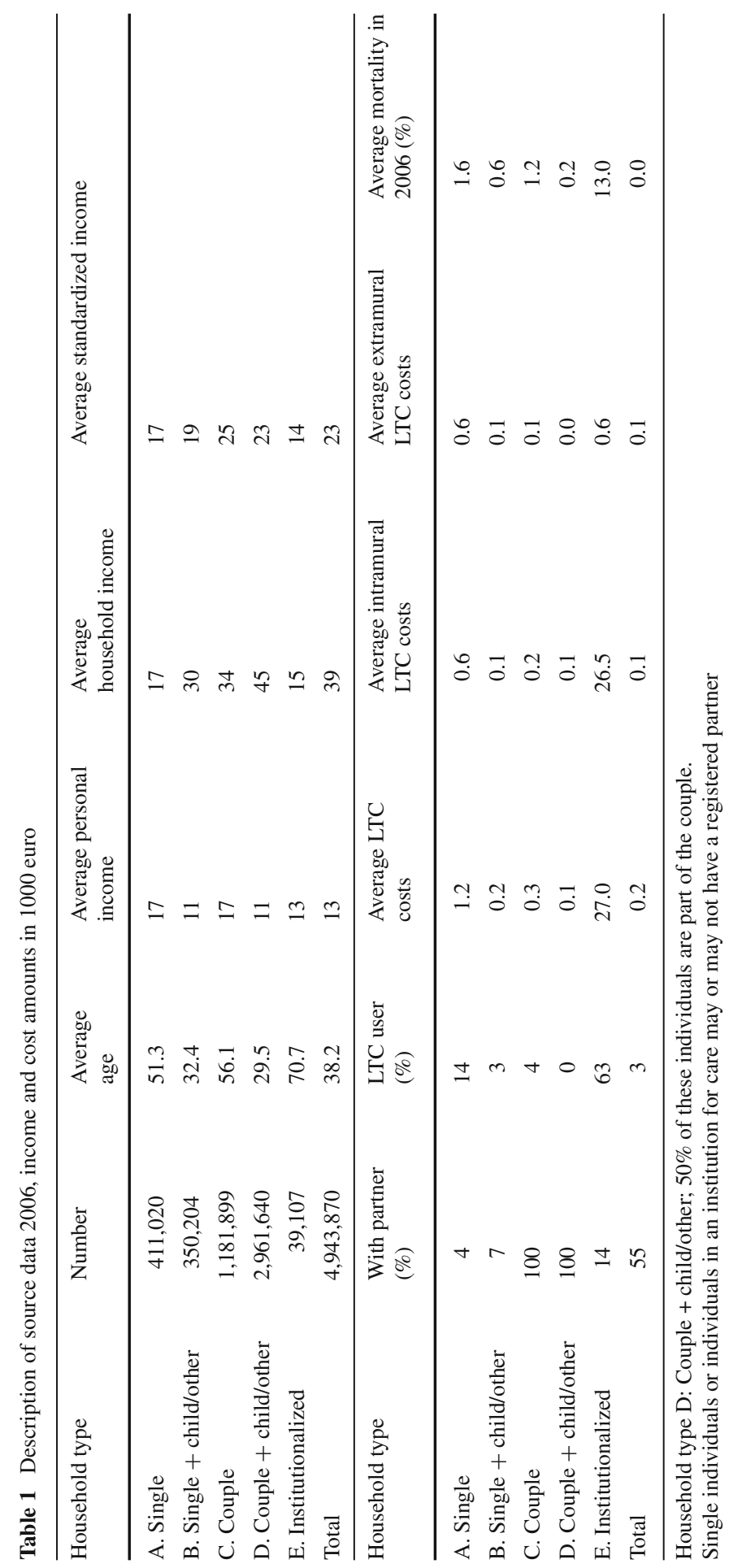



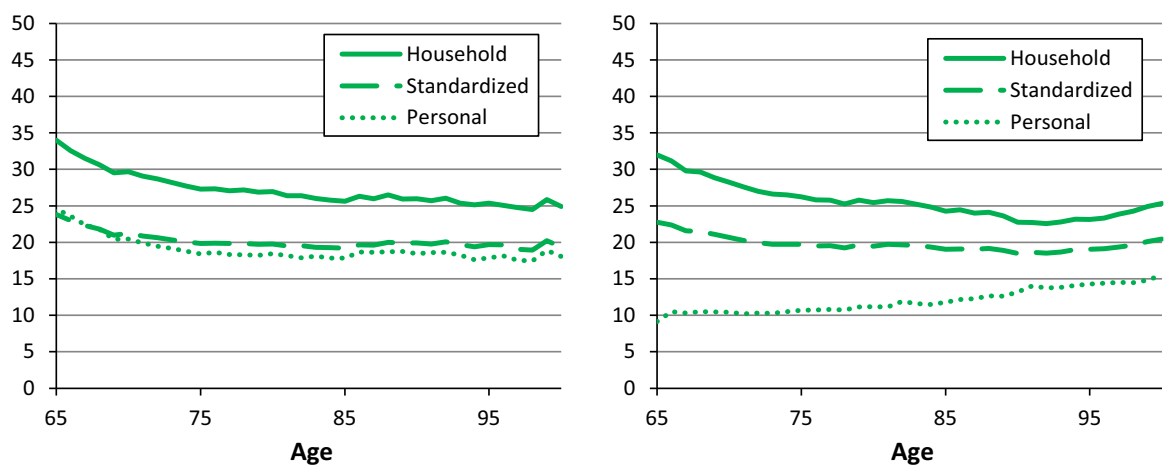

Fig. 1 Alternative income concepts in 1000 euros for ages 65+, average, males (left panel) and females (right panel)

disciplines (e.g. Farmer and Sidorowich 1987; Hsieh 1991) for purposes of prediction, conditional density estimation and time series resampling.

We make some modifications to the algorithm as proposed by Wong et al. (2015). The modifications allow us to simulate a multitude of random variables of interest, whilst taking into account the demographics age and sex of an individual. These variables are individual LTC costs, income, mortality, the household type ${ }^{4}$ and marital status $^{5}$ throughout the life-cycle. Also, we distinguish between spouses and other members of more persons households. The household type and marital status were taken into account alongside costs, income and mortality.

The essence of this modified algorithm can be described as follows. Consider the situation where we have a panel dataset over $2004-2006^{6}$, containing our variables of interest and demographic variables which are observed for each calendar year. The goal of the algorithm is to construct a synthetic life-cycle that contains a series of annual observations containing the variables, such that the life-cycles are 'realistic' in the sense that the life-cycles mimic the properties of the observed data. We will come back to this later on. For the construction we assume the random variables to follow a $p$ th order Markov process, in which we assume that the future states of the random variables at age $a$ depend on the states in the $p$ previous years (i.e. at age $a-1, \ldots$, $a-p$ ). We will refer to these previous states by 'history' hereafter. Because our data only spans the period 2004-2006, we choose $p=2$ out of necessity and assume that this is sufficient for our application. Wong et al. (2015) used $p=8$ to simulate acute health care costs, but also found that the differences with simulation using $p=2$

4 We differentiated between A: Single, B: Single + child(ren)/other person(s), C: Couple, D: Couple with child(ren)/other person(s), E: Institutionalized; where for individuals in A, B and E also marital status is taken into account.

5 Married includes officially living together using the CBS 2006 partner database. Note that Singles with or without children (A and B) and Institutionalized (E) can also have a partner. Taking the partner status into account next the household composition can be necessary when analyzing the ability to pay for the partner's LTC costs.

6 The method of NRRA requires a large number of source data. This is only available for the period 2004 to 2006. A longer period was not possible as the year 2007 is not completely available. 
were very modest. To illustrate the construction of a life-cycle under the NNRA, let us consider the following example in which we want to construct a synthetic lifecycle for a man. The life-cycle is initiated by randomly sampling an observation from zero-year old males in 2006. This observation contains the household income, LTC expenditures, mortality, household type and marital status of an actual individual at the end of age zero. These outcomes are then assigned to our synthetic male. Supposing this synthetic male survives at age zero, he then proceeds to receive an income (by being part of a household), incur expenditures and face the risk of death at age one.

To simulate these, we consider the synthetic history of up to this point-namely, his household income, LTC expenditures, as well as household type and marital status at age zero. ${ }^{7}$ Here the $k$-nearest neighbor method is applied: we consider the population of one-year old males in 2006 that had the same household and marital status at age zero (in 2005) as the synthetic individual, and search for $k$ individuals that are most similar to the synthetic individual (the $k$ nearest neighbors) in terms of the household income and LTC expenditures. The similarity can be computed by using a pre-defined distance measure to calculate the distance. We used the Euclidean distance:

$$
d=\sqrt{\left(I_{a-1}-I_{a-1}^{*}\right)^{2}+\left(C_{a-1}-C_{a-1}^{*}\right)^{2}+A\left[\left(I_{a-2}-I_{a-2}^{*}\right)^{2}+\left(C_{a-2}-C_{a-2}^{*}\right)^{2}\right]},
$$

where $I$ and $C$ are the observed percentile income and costs respectively, and where the asterisk denotes the value for the synthetic individual. $A$ denotes the indicator function for whether the synthetic individual was alive at $a-2$; in other words, whether they were born at or before age $a-2$. Percentiles are chosen over actual observed values, for two reasons. First, $I$ and $C$ have different scales, which implies that they have different weights in determining the distance. Ideally, these weights should be normalized. Secondly, we found a trend in income $7 \%$ for 2005-2006 and 3\% for 2004-2005), which implies that the absolute income values in 2004, 2005 and 2006 are not entirely comparable. The percentiles are used to deal with the different scales of the variables and the trends in these variables, as they are bounded between 0 and 1 and describe relative positions within a calendar year. Therefore we do not need to deflate the data. The $k$ nearest neighbors are those individuals that have the smallest distance to the synthetic individual. Out of the $k$ nearest neighbors, one neighbor is randomly drawn, and the expenditures and death status of this individual is assigned to the synthetic individual. Following Wong et al. (2015), we pick $k=2$. By stratifying the data by gender and age when searching for the nearest neighbors, we ensure that the gender and age patterns in the random variables are reflected in the synthetic lifecycles.

If the selected neighbor remains alive at age one, the synthetic individual will age one year and reach age two. We then look for a nearest neighbor from the population of two- year old males in 2006, based on the income and costs at age zero (in 2004) and

\footnotetext{
7 Naturally, at age zero, the individual is an unmarried child within the household. From age 18 onwards, household and marital status can vary strongly between individuals.
} 
one (in 2005), because we have a larger history of these individuals to our disposal. In other words, the simulation repeats itself for subsequent ages, each time using an updated history of income and costs (with the history length never exceeding $p=2$ ). The simulation ends when a nearest neighbor has been drawn that dies, in which case the synthetic individual dies as well.

There are some particularities to our NNRA algorithm. First, there are some modifications dealing with the presence of sparse strata in the data. For instance, few 18-year and 85-year olds are married (the latter because of sharp decreasing survival at that point of life), which means there are few potential candidates found in the data for being selected as a nearest neighbor. Whenever the potential number of nearest neighbors was $<10$, we repeatedly dropped one of the exact matching attributes (first household status, then marital status) until there were at least 10 potential nearest neighbors available. Ages 95 and up are generally sparse for both genders, so we pooled these ages together and considered them as one stratum ('age 95 and over'). Marital status was not considered as a criterion for ages 95 and up, as too few married individuals were present in the source data.

Second, at ages 95 and up complete separation may occur, which means that, conditional on a given income, costs, household and marital status, only nearest neighbors are found that all survive, due to small numbers of individuals with those income and costs levels. We considered this to be unrealistic, and thus decided to change the mechanism that assigns mortality status to the synthetic individual. Rather than basing the status on the drawn nearest neighbor, we fit a logistic regression model, in which the mortality is modelled as a function of a B-spline for age, a B-spline for costs at age $a-1$ and household position at age $a-1$ (income at $a-1$ and $a-2$, costs at age $a-2$ did not substantially improve the model fit based on the Akaike Information Criterium). Then the mortality rate $m$ is predicted for the specific nearest neighbor, and mortality status will be assigned by drawing from the Bernouilli distribution with parameter $m$. In some cases (96 for males and 164 for females) complete separation was still present. For these cases the synthetic life-cycle was terminated at the maximum ages as observed in the source data (105 for males and 108 for females).

By simulating a large amount of individuals $(n=10,000$ for men and women separately), we can ensure that the simulated life-cycles provide insight in the individual variation in LTC use over the life-cycle, as well as insight in the occurrence of individual shocks in LTC expenditures over time. Furthermore, the data can be used to estimate the relationship between LTC expenditures, income, and life expectancy. The resulting life-cycles can be interpreted as a cohort of newborns in 2006 and how they would accumulate income and LTC costs during an entire lifetime, under assumption that the levels of as well as transition probabilities of income and costs remain constant at those observed in the calendar year 2006, as well as the state of the long-term care system in 2006. The method replicates the 'true' transitional probabilities (e.g. death rate or probability of becoming a LTC-user), and the distribution of income and LTC from the source data conditional on the variables considered. As the population composition (e.g. by age and household type) in the synthetic life-cycle paths differs from the source data the total annualized amounts in the life-cycle paths are not equal to those amounts in the source data. The life-cycle paths are representative 
for a stationary population based on the behavior and institutions of the 2004-2006 period. Future changes in mortality and LTC use are therefore not taken into account explicitly.

Further justification for the use of the NNRA is given by Wong et al. (2015). The NNRA mimics the Markov Bootstrap (see Politis 2003) in the sense that the selection of one of the nearest neighbors is similar to the simulation of an observation from an estimate of the conditional density $f_{Z_{a} \mid Z_{a+1}, \ldots, Z_{a-p}}$, where $Z$ is the vector containing the random variables of interest. Nearest neighbor resampling based methods should provide approximately the same results as the Markov Bootstrap, as many consistency results have been proved for nearest neighbor density estimates based on Markov time series (see Yakowitz 1993). Wong also conducted an extensive assessment study, in which the method was used to simulate segments from the life-cycle (e.g. the costs from 0 to 8 year olds) and compare these segments to those observed in the original data. He found that the simulated segments have properties that mimic the properties of the original data (such as the distribution of costs over the entire segment, and the serial correlation) and found that the simulated life-cycles should therefore provide a realistic view of the evolution of acute health care expenditures over the entire lifetime.

We also conducted checks in which we compared some properties of the simulated life-cycles with those of the source data (see Appendix 2). Although they are similar, some differences were found in terms of life expectancy and LTC costs: the simulated individuals have a longer life expectancy and lower LTC costs than may be expected based on the mortality rates and average costs as observed in the source data. A plausible explanation for this is the presence of residual cohort effects that cannot be easily adjusted for. We use the zero-year olds of 2006 as the initial states for our synthetic individuals. When they reach the age of 65 for instance, comparing them to 65-year individuals as observed in 2006 is not straightforward, because the initial states of those observed individuals are likely to be different. In fact, it seems likely the synthetic individuals have initial better health and remain at better health for a longer time than those 65-year individuals. We see for example that the average LTC costs for a woman living in a couple at age 80 are $€ 2700$ in the source data and $€ 1400$ in the simulation which is roughly equally explained by a difference between the fraction of women using care (.33 vs .24) and the average amount when using care (€ 8400 and $€ 6000$ ). Comparing macro 2006 figures in the whole population with the simulation we see for average income, average LTC costs and fraction using LTC $€ 22,200$; $€ 600$ and $4.0 \%$ respectively for the source data and $€ 22,400$; $€ 900$ and $7.8 \%$ for the simulations. The average age in the source data is 42.5 and 45.5 for the simulations, therefore an older population on average.

\section{Distribution of LTC Expenditures Over the Life-cycle}

In this section we use the constructed life-cycle paths to analyze the life-cycle pattern of LTC costs. We consider the distribution of average costs over time in this section, and then turn to the spread in costs between individuals as a measure of idiosyncratic risks related to long-term care in Sect. 3.1. 


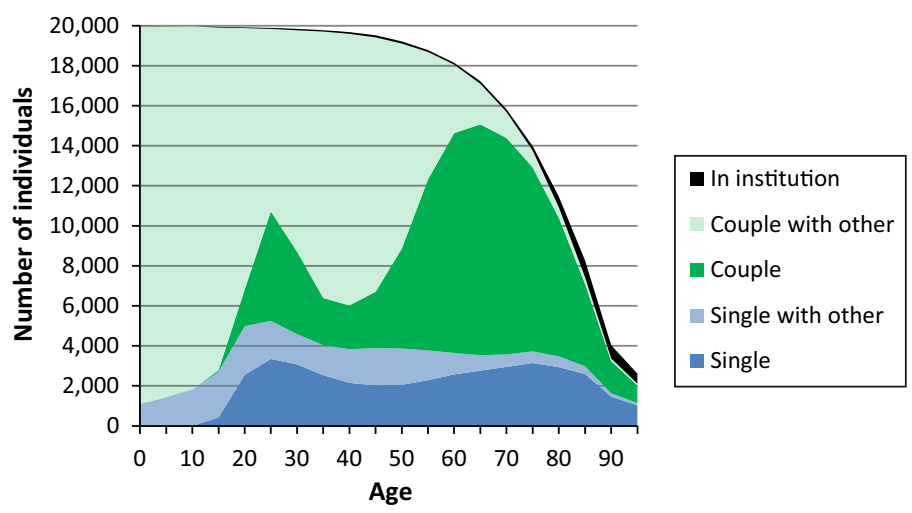

Fig. 2 Household type composition of the simulated population by age

\subsection{Distribution Over the Life-cycle}

To start, Fig. 2 shows how the household composition develops over the life-cycle using the simulated population. Together with age, household composition is a main determinant of LTC expenditures. ${ }^{8}$ We grouped the households into five types: single (living alone), a household of a single living with another person such as a child, a couple, a household of a couple living together with someone else such as a child, living in an institution. Starting with 20,000 individuals living as a child with a couple of parents or together with a single parent, the shares of living single or together as a couple increase at adulthood. Late in life the shares of individuals living alone and in an institution increase relative to the individuals living together.

Overall, the proportion of people that live in an institution is small. Only at high ages it rises to $19 \%$ in the age-group 95+. People using intramural care typically live in an institution. ${ }^{9}$ These characteristics of the development in household composition is an important underlying determinant of the distribution of LTC costs and standardized income over the life-cycle.

That LTC expenditures rise with age is shown in Fig. 3 (left panel); for women this rise is stronger than for men. This rising pattern can be explained in part by the rising probability to die in combination with the fact that LTC costs are also death related (Werblow et al. 2007; De Meijer et al. 2011). The relation between LTC expenditures and time to death (ttd) is shown in the right panel of the figure. All amounts are in euros of 2006 unless stated otherwise. Costs for females tend to be higher on average. The lower costs in year 0 from death as compared to year 1 are a result of care users

\footnotetext{
8 Lakdawalla and Philipson (2002) argue that growth of life expectancy of elderly males causes couples to stay married longer. This raises the supply of spousal care, and thus lowers the demand for formal (market) care. They claim that this explains why they find in the US that the growth of formal care relative to the elderly population decreased in the eighties despite of the growing share of output of LTC that is publicly financed by Medicaid, the falling birth rates with fewer children to care for their parents in lieu of a nursing home and increasing labor-force participation of young to middle-aged women.

9 The household type however is not always registered.
} 


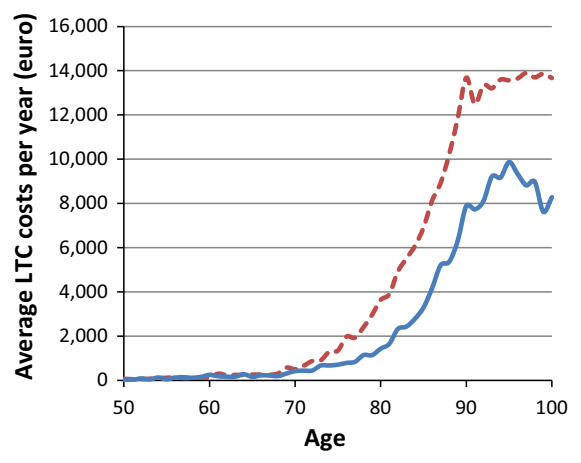

$-\infty$ females males

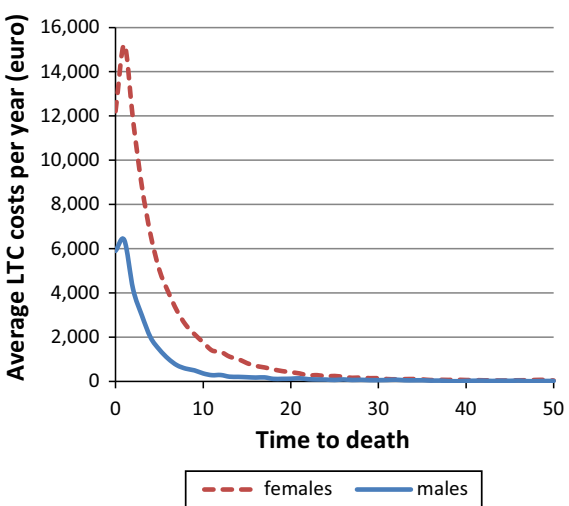

- - females males

Fig. 3 Average LTC costs per age (left) and per year before death (time to death) (right)

deceasing during the year as LTC costs are measured per calendar year; assuming that death occurs halfway this year, the cost as shown could be assumed to double per unit of time during the last months of life.

Time to death does not fully account for the rising cost with age, however. This can be seen in Figs. 4 and 5. Average time-to-death costs are split into different age groups showing that costs are substantially higher for older groups. This is true for both intramural care (Fig. 4) and extramural care (Fig. 5), and for men as well as women. For all age groups LTC is concentrated at the end of life but we see also that the older age groups, people living longer, have higher LTC costs. ${ }^{10}$ Applying a standardized linear regression of total annual LTC costs on time to death and age learns that about $60 \%$ of the LTC costs is related to age and $40 \%$ to the time to death. ${ }^{11}$ This finding is in line with e.g. Werblow et al. (2007) who also find that both time to death and age are important factors in explaining LTC costs.

These figures also show again that costs are higher for women than for men, both for intramural and extramural care. However, extramural care expenditures tend to be smaller in size and typically less concentrated at the end of life than intramural care. This is corroborated when calculating in which time span before death $50 \%$ of the total lifetime costs are spent. For total LTC costs this time span is 2.0 for men and 2.9 for women, and 2.7 years on men and women on average. As may be expected, the costs for intramural are more concentrated at the end of life than the extramural costs; the ' $50 \%$ ' time span is 2.1 years for intramural care and 5.8 years for extramural care. On average people start to use LTC as from 10 years before the end of their lives.

\footnotetext{
10 We should however consider the possibility that the presented effect is reinforced by a cohort effect that plays a role in constructing the life-cycle paths. As admission requirements to LTC have become stricter over the years in the Netherlands, the older cohorts deceasing in 2006 might have been admitted while not being as disabled as younger generations. The model might include this effect.

11 Standardization of both the dependent and the independent variables in a linear regression is technique to measure the relative size in importance of the independent variables in a multiple regression.
} 

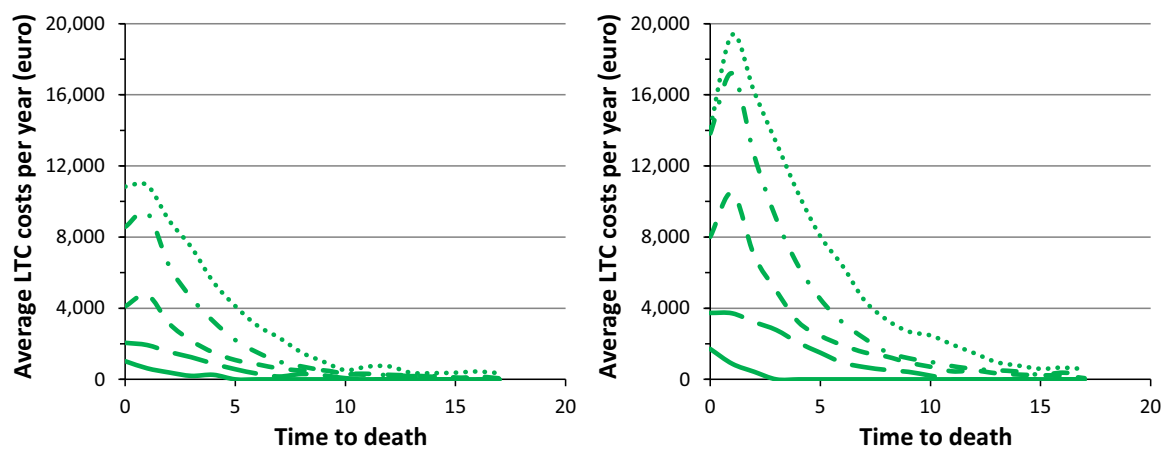

$-64-65-74--75-84-.85-94 \ldots . .95-$

$-64-65-74--75-84-\cdot 85-94 \cdots . .995-$

Fig. 4 Average intramural LTC costs per annum before death (time to death) per group with different ages at death, males (left), females (right)
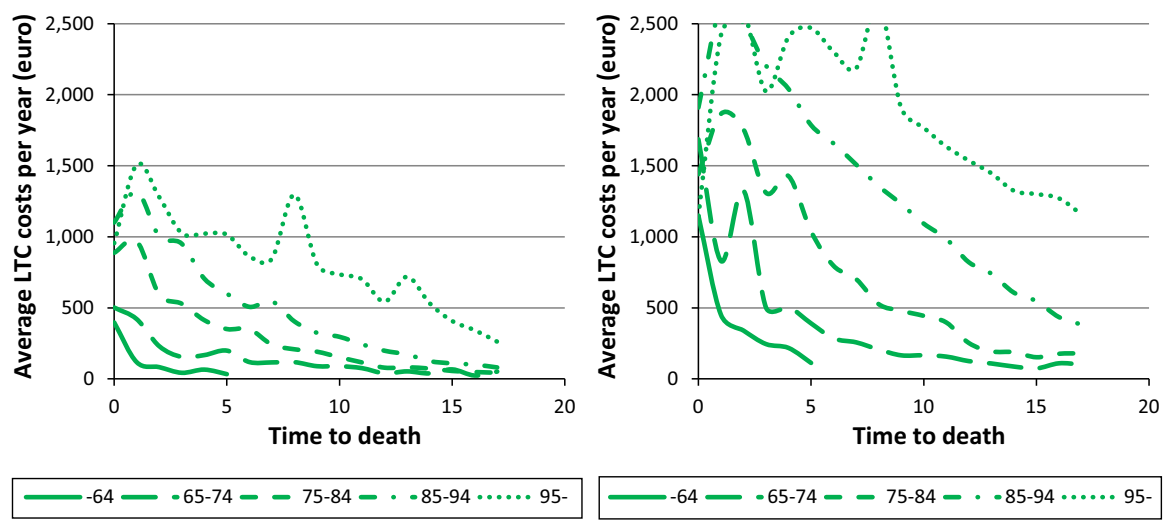

Fig. 5 Average extramural LTC costs per annum before death (ttd) per group with different ages at death, males (left), females (right)

\subsection{Distribution Across Individuals}

Next consider the distribution of LTC costs across individuals. This can be demonstrated by the Lorentz curve representing the cumulative distribution across individuals (see Fig. 6). ${ }^{12}$ This figure presents the distribution of LTC costs if measured on a yearly basis as well as on a life time basis. We focus on the costs beyond the age of 65. Before that age LTC costs tend to be small, and related to (youth) disability rather than old age care. If taken on a yearly basis the Lorentz curve shows that in $80 \%$ of the observations-i.e. individuals - the expenditures for LTC are virtually zero; costs are heavily concentrated in the remaining $20 \%$ of the observations. The distribution becomes substantially less unequal when taken over the remaining life-cycle at the age

12 In Fig. 6, the 45 degrees line would be the result if every individual has an equal part of the LTC costs. In this case the Gini coefficient would be zero. Lifetime costs are measured as the costs during the remaining life time starting from the age of 65 . 


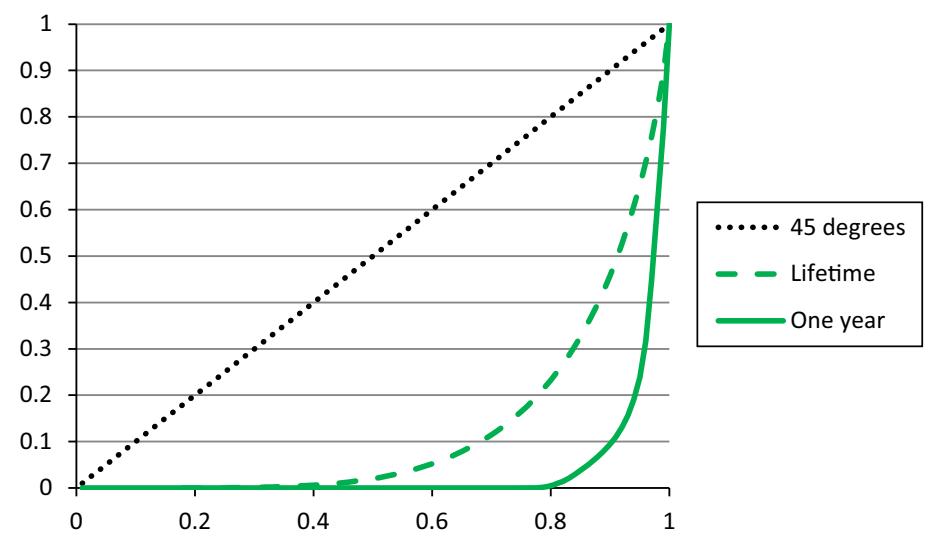

Fig. 6 Lorentz curve for LTC costs measured per year and measured over the remaining lifetime at the age of 65

Table 2 LTC costs in euro; average amounts and Gini coefficient

\begin{tabular}{lllllr}
\hline & \multicolumn{2}{l}{ Per year } & & & \multicolumn{2}{l}{ Life-time } \\
\cline { 2 - 3 } \cline { 5 - 6 } & Average amount & Gini & & Average amount & Gini \\
\hline Whole life & 729 & 0.98 & & 59,742 & 0.75 \\
$65+$ & 3,075 & 0.92 & & 64,091 & 0.74 \\
\hline
\end{tabular}

of 65 . But even then the costs are skewed. Here $80 \%$ of the observations (individuals on a lifetime basis) make up approximately $20 \%$ of the total expenditures; the remaining $80 \%$ can be attributed to other $20 \%$ of the population. Also in absolute terms costs are considerable for those who have bad luck; total costs over the $65+$ lifetime are as high as 300,000 euros at the $95 \%$ percentile, of which $85 \%$ consist of intramural costs. If this is taken as a probability it implies that people have an (unconditional) chance of $5 \%$ of running into costs of 300,000 euro for long-term care, in the absence of insurance.

Table 2 summarizes average costs and its distribution measured in yearly terms and in life-cycle terms, both for the whole life-cycle and for the 65-plus period of life only. The Gini coefficient measures inequality in these costs in absolute terms.

The table shows that the average annual LTC costs amount to 729 euros per year if measured over the full life-cycle; restricting the period to 65-plus raises average yearly costs to 3075 euro. If aggregated over the full life-cycle total costs on average amount to 59,742 , and for the 65 -plus period to 64,091 euro. ${ }^{13}$ The distribution of LTC costs is more even in lifetime terms than yearly terms; the Gini coefficient drops from 0.98 to 0.75 if measured over the full life-cycle, and from 0.92 to 0.74 if the period is restricted to the 65-plus period.

\footnotetext{
13 The fact that the $65+$ amounts are higher than the full lifetime amounts can be explained from the fact that these are different groups as the $65+$ group is restricted to survivors to this age.
} 
Table 3 65+ LTC costs, subdivided to sexes and intramural and extramural care

\begin{tabular}{|c|c|c|c|c|}
\hline & \multicolumn{2}{|l|}{ Per year } & \multicolumn{2}{|l|}{ Life-time } \\
\hline & Average amount & Gini & Average amount & Gini \\
\hline \multicolumn{5}{|c|}{ Total LTC } \\
\hline Males & 1890 & 0.95 & 35,443 & 0.81 \\
\hline Females & 3992 & 0.89 & 91,090 & 0.66 \\
\hline Total & 3075 & 0.92 & 64,091 & 0.74 \\
\hline \multicolumn{5}{|c|}{ Intramural } \\
\hline Males & 1521 & 0.97 & 28,523 & 0.87 \\
\hline Females & 2979 & 0.94 & 67,979 & 0.76 \\
\hline Total & 2343 & 0.95 & 48,836 & 0.81 \\
\hline \multicolumn{5}{|c|}{ Extramural } \\
\hline Males & 369 & 0.95 & 6921 & 0.79 \\
\hline Females & 1013 & 0.88 & 23,111 & 0.64 \\
\hline Total & 732 & 0.91 & 15,256 & 0.72 \\
\hline
\end{tabular}

Table 3 shows the differences between sexes and intramural and extramural care.

We find a large difference in LTC use between the sexes. Annual costs of females turn out to be 2.1 times as high as those of males: 3992 euros relative to 1890 euros per year on average beyond the age of 65 (Table 3). The larger part of these costs relates to intramural care, both for men and for women. The differences in the Gini-coefficient indicate that the dispersion of LTC use turns out to be bigger for intramural care than for extramural care. Finally, costs for males are more unevenly distributed than for women; apparently, ending up in intensive extramural and intramural care is more exceptional for men than for women.

In conclusion, we see that intramural costs are higher and more skewed than extramural costs. Moreover, intramural costs are more concentrated at the end of life than extramural costs. Both factors indicate that there is less scope for self-insurance for intramural costs than for extramural costs. The next section will look deeper into the possibilities for self-insurance of LTC costs by smoothing them over the life-cycle.

\section{Ability to Pay for LTC}

When examining alternative financing policies such as higher co-payments for long term care it is important to know how much individuals could pay from their current or lifetime income. The life-cycle perspective allows us to analyze the potential for self-insurance by smoothing (temporary) shocks over the life-cycle. This may help to mitigate the traditional trade-off between insurance and moral hazard. A problem that is typical for long-term care, however, is that costs are concentrated at the last stages of life. If shocks are revealed that late in life, the opportunities for smoothing are limited. When calculating the present value of costs and income we use a growth corrected 


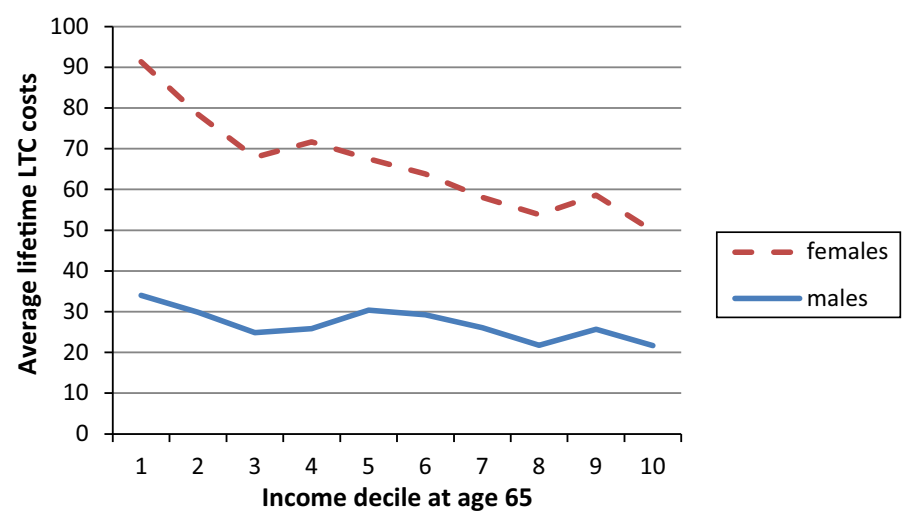

Fig. 7 Average lifetime LTC costs in 1000 euro's in relation to income distribution

discount rate of 1.5 per cent, that is 3.0 risk adjusted return minus $1.5 \%$ growth rate. ${ }^{14}$ Figure 7 shows how total life-cycle LTC expenditures vary with income at the age of 65. ${ }^{15,16}$ This negative relation - for women stronger than for men - implies that higher incomes have lower LTC expenditures. This is so, despite of the longer life expectancy of higher incomes. ${ }^{17}$ This could be because they are more healthy, or organize their care in other-private-ways. ${ }^{18}$ A similar negative association is found in several other studies reviewed in Einiö (2010) usually attributed to the lower probability of admission to long-term institutional care. ${ }^{19}$

This result shows that public LTC has a redistributive impact in favor of lower incomes on average. It does provide little insight, however, into the idiosyncratic variability of LTC costs in relation to income, and thus into the ability to pay for LTC at the household level. To assess the ability to pay for LTC we therefore turn to a household perspective. We consider costs and income at a household level here, rather than standardized individual income, to take account of the mutual insurance between members of the household. Table 4 analyses the distribution of total LTC costs for households and relates this to the full household income. The Gini coefficients

\footnotetext{
14 Averages per year are not discounted.

15 The income measure used here is standardized income. It thus takes account of family size and composition and can be regarded as a better measure of welfare than the uncorrected measure of income.

16 As cohort effects lead to lower income for older cohorts we use an income percentile per age, a relative income measure as also explained in Sect. 2.2. Analyses show that the results do not change when we use income at the age of 65 instead of average income over the period ages 65 and older. Therefore we only used the former.

17 A similar result for the Netherlands is found by Bakx et al. (2013). They show that people in the lowest quartile of the income distribution have much higher LTC costs than those in the highest quartile. However, the income effect becomes much smaller when they control for demographic information and prior LTC use.

18 This negative association is robust for using other discount rates.

19 Einiö (2010) reviewed a range of studies on this aspect for several countries. In part of these studies household income was inversely associated with the risk of admission to long-term institutional care; in the other part most studies did not find a clear association with income.
} 
Table 4 LTC costs and income on yearly basis and life time basis for ages $65+$

\begin{tabular}{lllllr}
\hline & \multicolumn{2}{l}{ Per year } & & & Life-time \\
\cline { 2 - 3 } \cline { 5 - 6 } & Average amount & Gini & & Average amount & Gini \\
\hline LTC costs & 4475 & 0.91 & & 69,821 & 0.71 \\
Income & 27,307 & 0.28 & & $4,84,740$ & 0.33 \\
Fraction & $16 \%$ & & $14 \%$ & \\
\hline
\end{tabular}

Table 5 LTC costs as a fraction of income on household level, per year and lifetime 65+

\begin{tabular}{|c|c|c|c|c|}
\hline & \multicolumn{2}{|l|}{ Per year } & \multicolumn{2}{|l|}{ Life-time } \\
\hline & Average amount & Gini & Average amount & Gini \\
\hline LTC costs & $30 \%$ & 0.92 & $19 \%$ & 0.76 \\
\hline
\end{tabular}

point again to a very skewed distribution in LTC costs - despite the mutual insurance between partners-, much stronger than inequality in income. On the yearly basis the Gini coefficient is 0.91 for LTC while for income it is only 0.28. Also if taken over the $65+$ life-cycle inequality in LTC costs is still high with a Gini coefficient of 0.71 vis-à-vis 0.33 for income.

More important than the distributions of LTC and income separately is the correlation between costs and income at the household level. As a first step Table 5 presents the averages and Gini coefficients for the fraction of LTC to income for all individuals both on a yearly basis and on a lifetime (65-plus) basis. Both are relevant: on a yearly basis it matters if (liquidity) constraints prohibit smoothing over time; on a lifetime basis it matters for the distribution of (net) income available for consumption. $^{20}$

Interestingly, the average of the fractions of LTC to income is substantially lower than the sum of costs as a fraction of the sum of income, both on a yearly basis $(30 \%$ vis a vis $16 \%$ ) as on a life-time basis $(19 \%$ vis a vis $14 \%){ }^{21}$ This is a result of the unevenness in income and especially LTC costs and the concentration of costs at lower incomes. Even though the average fraction of LTC to income is only $19 \%$ on a life-time basis $(65+)$ it is clear that there is a need for insurance. First, on a yearly basis the average fraction is much higher, namely 30 per cent. This implies that if people are unable to smooth, LTC takes a substantially higher proportion of income on average. This is all the more relevant as LTC costs are concentrated at the end of life thereby limiting the possibilities for smoothing. The concentration of LTC costs at the end of life is illustrated in Fig. 8 showing how average LTC costs over the remaining

\footnotetext{
20 Here we consider this partial covariance; a more complete analysis would require inclusion of all other sources of net incomes and costs, so including the full tax benefit system.

21 The lifetime figures are discounted to age 65 and therefore lower than the per year amounts. Because of the discounting and the difference in duration the fraction of LTC costs of income Gini in the lifetime column of $16 \%$ differs from the per year fraction of $14 \%$.
} 


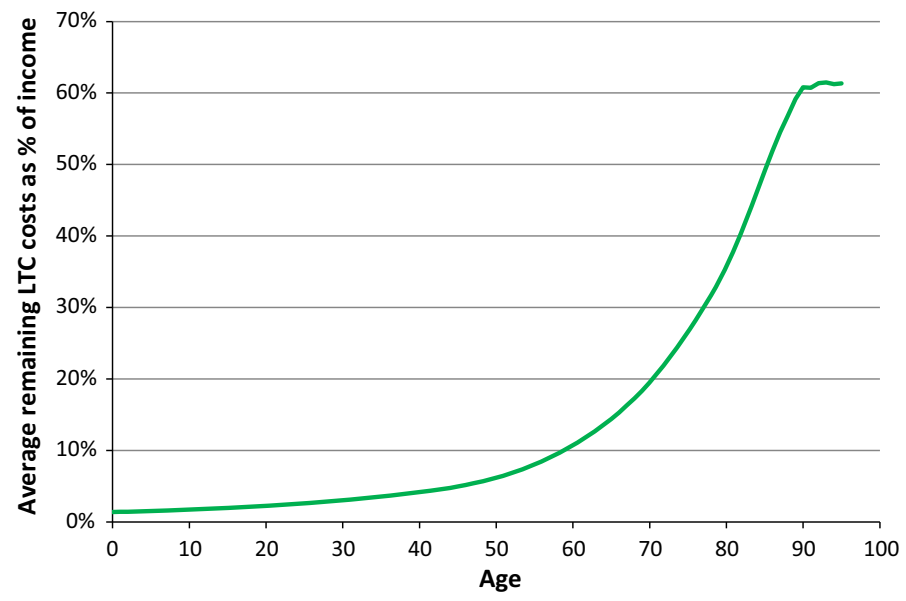

Fig. 8 Ratio of LTC costs to income over remaining lifetime across ages

Table 6 Part of LTC \% costs for population aged $65+$ which is payable from household income $65+$

\begin{tabular}{llll}
\hline & Per year & Life-time after shock & Life-time \\
\hline Part LTC costs payable & $47 \%$ & $64 \%$ & $93 \%$ \\
\hline
\end{tabular}

life-cycle increases with age. At the age of 65 average expected LTC costs amount to $16 \%$ of income, increasing to $25 \%$ at the age of 70 , and even $40 \%$ at the age of 80 . The ability to absorb LTC shocks by smoothing over remaining lifetime therefore rapidly deteriorates when people become older.

As a final step we can assess the scope for increasing out of pocket expenses by the following simple and extreme exercise. We emphasize that it concerns a hypothetical case only, just to get a rough indication for the maximum ability to pay LTC from private income. Assume that all costs are shifted to households up to a limit of $100 \%$ of income. How much of total expenditures on LTC would then be covered by income? This outcome could be seen as an upper limit for privatization. Clearly, this is an extreme case, but not totally unrealistic as high costs normally imply institutionalized care, in which case practically all costs for housing, food and other daily expenses are included in LTC expenditures. Table 6 gives the fraction of total LTC costs that would be paid by individuals on average if each household would pay all costs up to a maximum of $100 \%$ of income. If applied on a yearly basis this would allow some $47 \%$ of total costs to be privatized; if done on a lifetime (65-plus) basis this would increase to $93 \%$.

Obviously, this latter estimate is unrealistic as it presupposes that the costs already can be anticipated for at the age of 65 . Therefore we do another exercise taking into account that costs can only be smoothed after the shock has revealed. A health shock is here defined as the moment a household has had at least 10,000 euros of LTC costs 
in total since the age of $65 .{ }^{22}$ Applying this rule, we find that a fraction of $64 \%$ of total LTC cost could be paid out of private income (see the middle column in Table 6). This is significantly lower than if costs would be revealed at the age of 65, but higher than if costs would be capped on a yearly basis.

Taken together these results indicate that although LTC costs feature only $6 \%$ of income over the full life-cycle, the scope for self-insurance is limited for two fundamental reasons. First, LTC costs are highly unevenly distributed across households, and second, the costs are revealed only late in life. Even taking this into account, there is scope for increasing co-payments, for example by co-payments up to some maximum fraction of income. This is not to say that this is optimal from a welfare point of view. Co-payments of up to $100 \%$ of income during the rest of your life, leaving nothing for other consumption, is obviously not optimal from an insurance perspective.

\section{Conclusion}

The explosive mix of rising LTC costs together with population ageing puts pressure on current collective arrangements for long-term care. Future LTC costs in the Netherlands are expected almost to double as a fraction of GDP in the next decades, even despite reforms recently installed by the Dutch government. In order to avoid the burden being shifted to future generations one should consider ways to improve efficiency, and increase contributions of older generations. This paper explores the scope for shifting the balance from collective insurance to private 'self-insurance'. From a life-cycle perspective smoothing (temporary) income shocks over the life-cycle may constitute an alternative to collective insurance, reducing welfare losses due to shocks and at the same time avoiding moral hazard problems innate to (collective) insurance schemes.

We employ a life-cycle analysis to study the distribution of long-term care (LTC) costs at the household level. Applying the so called "nearest neighbor resampling approach" (NNRA) to Dutch administrative panel data for the period 2004-2006 we have constructed a set 20,000 life-cycles for LTC, income and household composition at the individual level. Using these life-cycles we first find the usual features of rising LTC expenditures with age and time to death, and more so for women than for men. The data also shows higher LTC use for singles than for more-person households. More interestingly — exploiting the life-cycle structure-we find that the distribution of LTC costs is highly skewed, but less so when measured over the life-cycle than on a yearly, cross-sectional basis. The distribution of LTC is far more unequal than the distribution of income. Moreover, lifetime LTC expenditures are higher for low income households than for richer households, even in absolute terms. Finally, the need for LTC is concentrated late in life, thereby further limiting the scope for smoothing. This makes LTC different from other policy domains such as social security where shocks are revealed earlier in life. All these factors limit the scope for self-insurance for LTC; there thus remains a clear need for (collective) insurance. Yet it is possible to

\footnotetext{
22 More than half (54\%) of all people attaining the age of 65 will reach this level of LTC costs at some point in their lives. This group of people represents almost $99 \%$ of total LTC costs measured over the life-cycle from 65 .
} 
increase private co-payments, in particular for higher incomes, provided that the copayments are capped at some reasonable level of income. Here it is interesting to make a distinction between intramural care and extramural care. The costs for extramural care are lower on average, and moreover better distributed over life, increasing the scope for self-insurance of this type of costs. In the extreme case that private payments are capped at $100 \%$ of lifetime income (from the moment that the shock is revealed), we find that $64 \%$ of total LTC expenditures could be financed by private co-payments. Clearly, this is an extreme. We have not analyzed optimal private co-payments from a welfare point of view as this is not in the scope of this paper. It may serve, however, as a rough indication for the scope for increasing private contributions to LTC; under the system prevailing in the observation period private co-payments amounted to only $10 \%$.

Our analysis provides insight into the distribution of LTC both from a longitudinal perspective (over the individual life-cycle) as well as a cross sectional perspective (across households). There are some limitations too. First, the observation period is restricted, and already somewhat older, namely 2004-2006. This is due to data limitations, and also because we want the system to be steady during the period, in order to single out cohort effects as much as possible. A longer period would have allowed us to construct more complete life-cycles, and better checks on robustness. Furthermore, our simulations are restricted to a stationary population. This is sufficient for the type of (policy) analysis, as in this paper, but makes it less suitable for analyzing the evolution of LTC expenditures over time. Another limitation, due to the data set, concerns the limited number of variables taken into account. Future research could attempt to extend the observation period and include more variables. Nevertheless, also the current data is already unique in combining the life-cycle and the household perspective, and may serve as a starting point for further analysis on the distribution and options for public and private insurance in the domain of long-term care.

Open Access This article is distributed under the terms of the Creative Commons Attribution 4.0 International License (http://creativecommons.org/licenses/by/4.0/), which permits unrestricted use, distribution, and reproduction in any medium, provided you give appropriate credit to the original author(s) and the source, provide a link to the Creative Commons license, and indicate if changes were made.

\section{Appendix 1: Source Data}

This paper uses administrative micro data on LTC use and expenditures from the Administrative Office Exceptional Medical Expenses (Centraal Administratiekantoor$\mathrm{CAK})^{23}$, and mortality from the Death Causes Registry for the entire Dutch population and administrative data and survey data on all income sources from Statistics Netherlands (Regionaal Inkomensonderzoek-RIO) and marital status from Statistics Netherlands (Gehuwdheidsbestand VRLHUWELIJKSGESCHIEDENISBUS). All this micro data has been made available by Statistics Netherlands (CBS). It covers the period from 2004 to 2006 . They include many of the important variables as age,

23 See supporting Information for the translation from LTC use in time units to expenditures in euro's. 
Table 7 Comparison of source data (RIO) and macro data (CBS) at age 0

\begin{tabular}{llll}
\hline 2006, age 0 & Number of individuals & \% Female & Average income \\
\hline Database RIO & 54,260 & 48.4 & 20,450 \\
Database RIO, applying weights & 184,185 & 48.3 & 20,328 \\
CBS & 185.057 & 48.7 & $20,211^{*}$
\end{tabular}

* Not available, derived from age group 0-4 years 19,900 and figure for this age group in Database RIO 20,015

gender, household composition and household income. Education level, health status and disability are not available. The data used consist of all individuals from RIO 2006 who are alive end of year 2005. In these years RIO is a weighted sample from the whole population. For each individual data is complemented with:

- RIO 2005 and 2004

- Partner data if an individuals is not living with a partner according to RIO but the individual does appear in the CBS partner 2006 database

- LTC costs. Derived from LTC use in hours/days in the CAK database and the tariffs as used by the Dutch Health Authority (NZA) for extramural care and derived from the CAK and CVZ annual reports for intramural care. ${ }^{24}$

- The following household types are distinguished:

10: single; 11: 10 with partner elsewhere

20: single living with child(ren) or other person(s); 21: 20 with partner elsewhere

31: couple

41: couple living with child(ren) or other person(s)

42: child or other person living with couple

50: living in institution; 51: living in institution with partner (in institution or elsewhere)

Table 7 shows how the used source data matches macro data for the 20,000 individuals used to start the simulation (population at age 0 ).

As there are no large differences between the weighted and unweighted RIO data and the CBS data it is not necessary to control for the weights in the RIO database to start the simulation. Table 8 shows how the used source data matches macro data for the whole population.

This data shows that there are differences for average LTC costs between the unweighted and the weighted sample. However further analysis shows that within the applied strata as explained in Sect. 2 the weights do not lead to differences. ${ }^{25}$ As the NNR method only matches within the imposed strata weighting is also not necessary after age 0 .

\footnotetext{
24 We use one average tariff for both kinds of intramural care ("verpleeghuis" and "verzorgingstehuis") of 145.14 euro per day (2006).

25 We would not expect differences as RIO weights are used to match the macro figures on non institutionalized inhabitants and focus on regional differences.
} 
Table 8 Comparison of source data (RIO) and macro data (CBS) for all ages

\begin{tabular}{llllll}
\hline 2006 & $\begin{array}{l}\text { Number of } \\
\text { individuals }\end{array}$ & \% Female & $\begin{array}{l}\text { Average } \\
\text { income }\end{array}$ & $\begin{array}{l}\text { Average LTC } \\
\text { costs }\end{array}$ & \% Care user \\
\hline $\begin{array}{l}\text { Database RIO } \\
\begin{array}{l}\text { Database RIO, applying } \\
\text { weights }\end{array}\end{array}$ & $4,943,870$ & 49.7 & 22,760 & 444 & 3.1 \\
CBS & $15,916,709$ & 50.7 & 21,868 & 717 & 4.5 \\
\hline
\end{tabular}

* Not available at CBS. Figure RIVM 2007 Source RIVM Cost of Illness database 2013, www.costofillness. $\mathrm{nl}$

** Not available for whole population. Figure derived from population $18+(6.54)$ and figure for this age group in Database RIO (5.75)

\section{Appendix 2: Comparison of Source Data and Life-cycle Paths}

By way of check on the life-cycle paths we analyze how well the aggregated lifecycle paths mimic the aggregates of the source data (both expressed as average per individual). In general, the life-cycle paths mimic the aggregates from underlying data very well, except at higher ages where we see lower LTC use and costs in the life-cycle paths. This is coherent with the duration of life which is higher in the paths than in de source data. This may be the result of some specific cohort effects in the source data (Figs. 9, 10, 11, 12, 13, 14, 15, 16).

When evaluating policy alternatives one could allow for this effect by performing a sensitivity analysis.
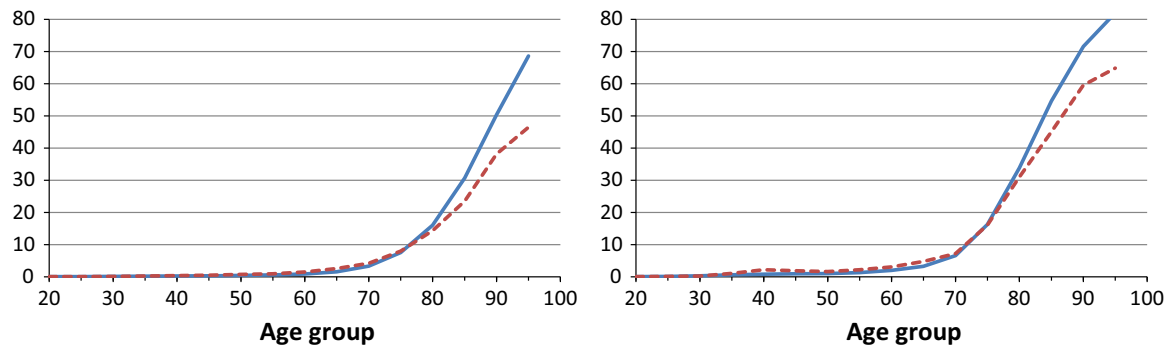

Fig. 9 Percentage LTC User (males left, females), source (blue line) versus paths (red dashed), all household types. (Color figure online)
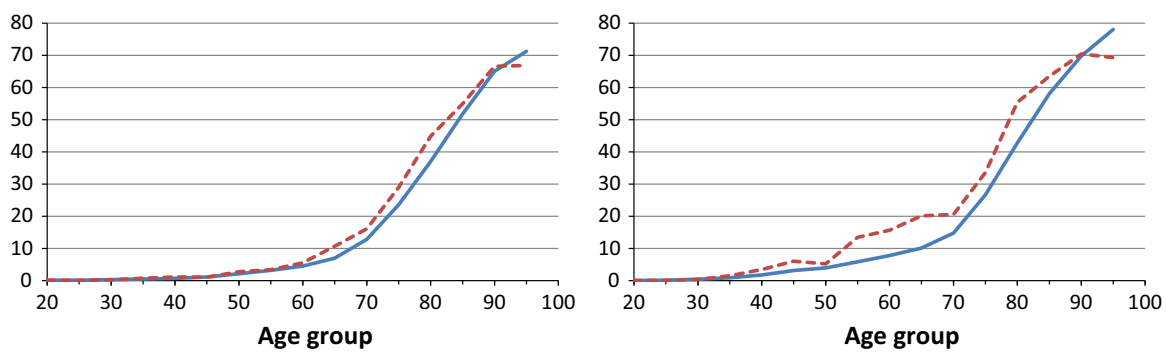

Fig. 10 Percentage LTC User (males left, females), source (blue line) versus paths (red dashed), single households. (Color figure online) 

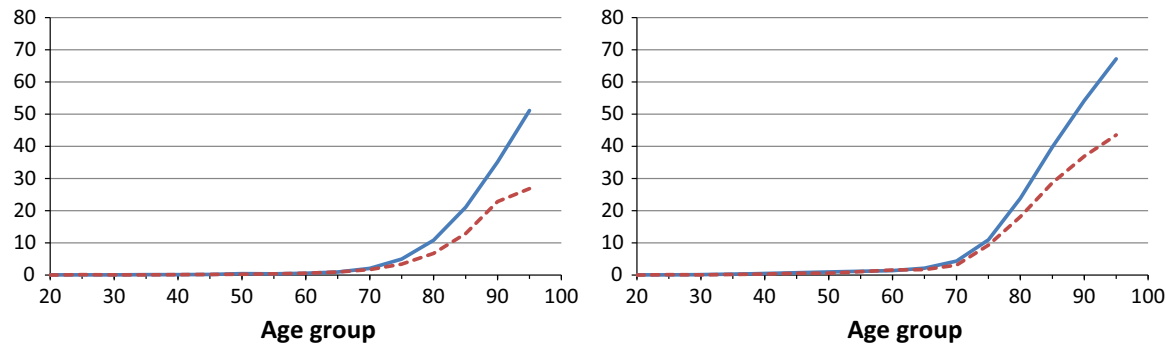

Fig. 11 Percentage LTC User (males left, females), source (blue line) versus paths (red dashed), couples. (Color figure online)
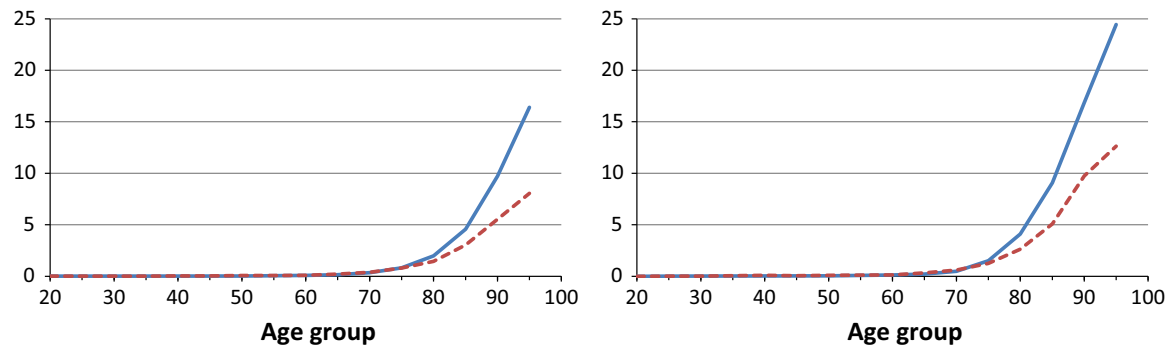

Fig. 12 Average LTC use (1000 euro) (males left, females), source (blue line) versus paths (red dashed), all households. (Color figure online)
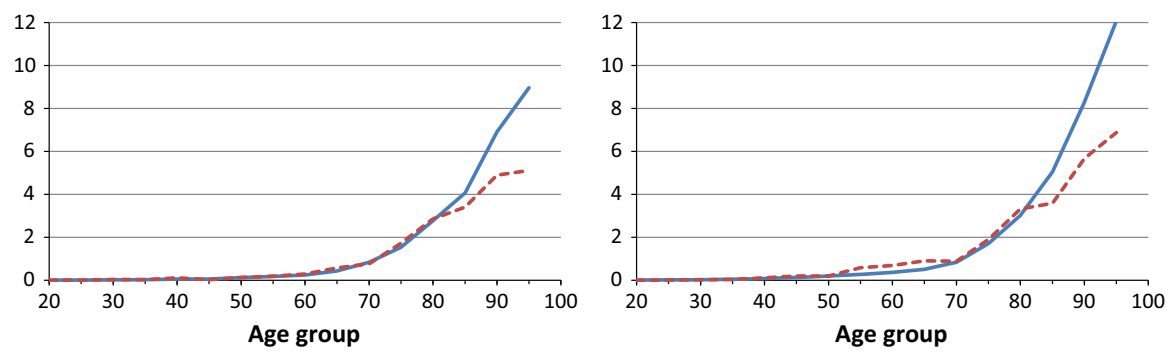

Fig. 13 Average LTC use (1000 euro) (males left, females), source (blue line) versus paths (red dashed), singles. (Color figure online)
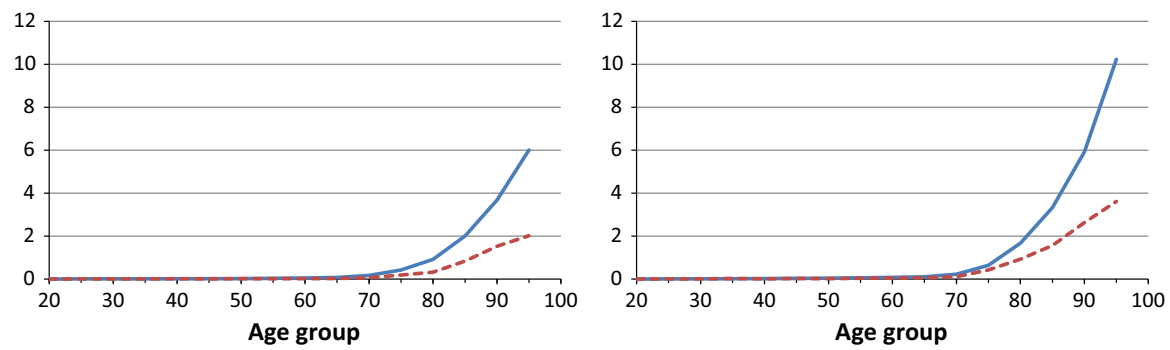

Fig. 14 Average LTC use (1000 euro) (males left, females), source (blue line) versus paths (red dashed), couples. (Color figure online) 

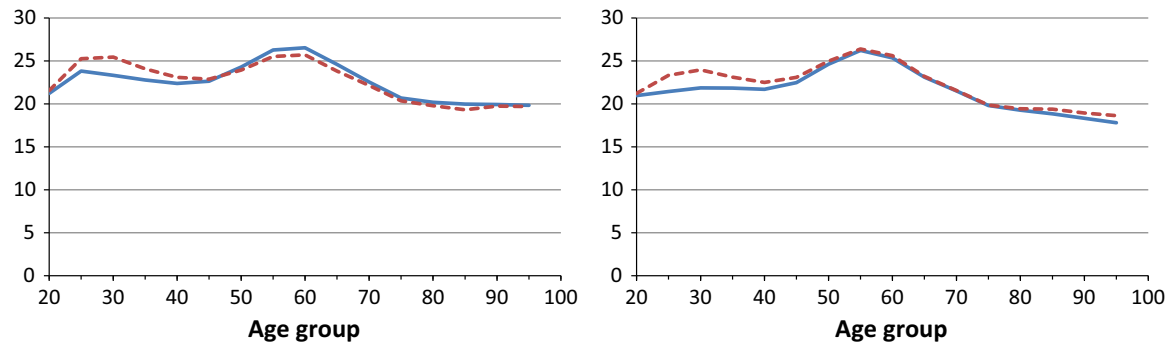

Fig. 15 Average Standardized Income (1000 euro) (males left, females), source (blue line) versus paths (red dashed), all household types. (Color figure online)
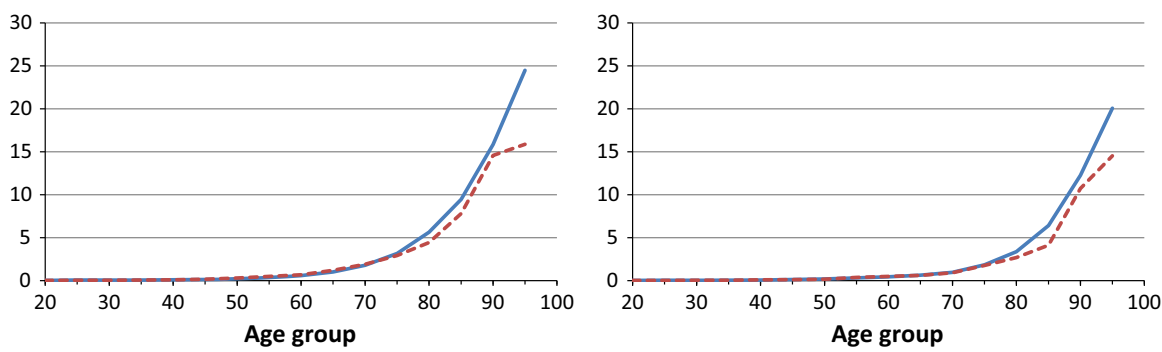

Fig. 16 Average mortality (males (left), females), source (blue line) versus paths (red dashed), all household types. (Color figure online)

\section{References}

Ameriks, J., Caplin, A., Laufer, S., \& Van Nieuwerburgh, S. (2011). The joy of giving or assisted living? Using strategic surveys to separate public care aversion from bequest motives. The Journal of Finance, 66(2), 519-561.

Bakx, P., Schut, E., \& van Doorslaer, E. (2013). Can risk adjustment prevent risk selection in a competitive long-term care insurance market? Tinbergen Institute Discussion Paper, TI 2013-017/V.

Bakx, P., Meijer, C., Schut, F., \& Doorslaer, E. (2015). Going formal or informal, who cares? The influence of public long-term care insurance. Health Economics, 24(6), 631-643.

Bakx, P., \& De Meijer, C. (2013). The influence of spouse ability to provide informal care on long-term care use. doi:10.2139/ssrn.2407926

Bhattacharya, J., \& Lakdawalla, D. (2006). Does medicare benefit the poor? Journal of Public Economics, 90(1), 277-292.

Bonenkamp, J., Nusselder, W., Mackenbach, J., Peters, F., \& ter Rele, H. (2013). Herverdeling door pensioenregelingen: De invloed van de gestegen levensverwachting en het Regeerakkoord, Netspar design paper 16. Tilburg: Netspar.

Bovenberg, A., Hansen, M. I., \& Sørensen, P. B. (2012). Efficient redistribution of lifetime income through welfare accounts. Fiscal Studies, 33(1), 1-37d.

Brown, J., \& Warshawsky, M. (2013). The life care annuity: A new empirical examination of an insurance innovation that addresses problems in the markets for life annuities and long-term care insurance. Journal of Risk and Insurance, 80(3), 677-704.

De Nardi, M., French, E., \& Jones, J. B. (2009). Why do the elderly save? The role of medical expenses (No. w15149). Cambridge: National Bureau of Economic Research.

De Nardi, M., French, E., Jones, J. B., \& McCauley, J. (2015). Medical spending of the US Elderly (No. w21270). Cambridge: National Bureau of Economic Research.

De Meijer, C., Koopmanschap, M., Uva, T. B., \& van Doorslaer, E. (2011). Determinants of long-term care spending: Age, time to death or disability? Journal of Health Economics, 30(2), 425-438. 
De Meijer, C., Majer, I., Koopmanschap, M., \& van Baal, P. (2012). Forecasting lifetime and aggregate long-term care spending in the Netherlands: Accounting for changing disability patterns. Medical Care, 50(8), 722-729.

De Meijer, C., Bakx, P., Doorslaer, E., \& Koopmanschap, M. (2015). Explaining declining rates of institutional LTC use in the Netherlands: A decomposition approach. Health Economics, 24(S1), 18-31.

Einiö, E. (2010). Determinants of institutional care at older ages in Finland. Finnish Yearbook of Population Research, 45.

European Commission. (2015). The 2015 Ageing Report: Economic and budgetary projections for the 28 EU Member States (2013-2060), European Economy 3/2015.

Farmer, J. D., \& Sidorowich, J. J. (1987). Predicting chaotic time series. Physical Review Letters, 59(8), 845.

Finkelstein, A., Luttmer, E. F., \& Notowidigdo, M. J. (2013). What good is wealth without health? The effect of health on the marginal utility of consumption. Journal of the European Economic Association, 11(s1), 221-258.

Francesca, C., Ana, L. N., Jérôme, M., \& Frits, T. (2011). OECD health policy studies help wanted? Providing and paying for long-term care: Providing and paying for long-term care (Vol. 2011). Paris: OECD Publishing.

French, E., \& Jones, J. B. (2004). On the distribution and dynamics of health care costs. Journal of Applied Econometrics, 19(6), 705-721.

Halliday, T. (2011). Health inequality over the life-cycle. The BE Journal of Economic Analysis and Policy, 11(3), 1-21.

Hsieh, D. A. (1991). Chaos and nonlinear dynamics: Application to financial markets. The Journal of Finance, 46(5), 1839-1877.

Koopmanschap, M., de Meijer, C., Wouterse, B., \& Polder, J. (2011). Determinants of health care expenditure in an aging society. Netspar panel paper 22. Tilburg: Netspar.

Lakdawalla, D., \& Philipson, T. (2002). The rise in old-age longevity and the market for long-term care. American Economic Review, 92(1), 295-306.

Lubitz, J., Cai, L., Kramarow, E., \& Lentzner, H. (2003). Health, life expectancy, and health care spending among the elderly. New England Journal of Medicine, 349(11), 1048-1055.

Mackenbach, J. P., Kunst, A. E., Cavelaars, A. E., Groenhof, F., Geurts, J. J., \& EU Working Group on Socioeconomic Inequalities in Health. (1997). Socioeconomic inequalities in morbidity and mortality in Western Europe. The Lancet, 349(9066), 1655-1659.

McClellan, M., \& Skinner, J. (2006). The incidence of medicare. Journal of Public Economics, 90(1), 257-276.

Murtaugh, C. M., Spillman, B. C., \& Warshawsky, M. J. (2001). In sickness and in health: An annuity approach to financing long-term care and retirement income. Journal of Risk and Insurance, 68(2), 225-254.

Nihtilä, E., \& Martikainen, P. (2007). Household income and other socio-economic determinants of longterm institutional care among older adults in Finland. Population Studies, 61(3), 299-314.

Nihtilä, E., \& Martikainen, P. (2008a). Institutionalization of older adults after the death of a spouse. American Journal of Public Health, 98(7), 1228-1234.

Nihtilä, E., \& Martikainen, P. (2008b). Why older people living with a spouse are less likely to be institutionalized: The role of socioeconomic factors and health characteristics. Scandinavian Journal of Public Health, 36(1), 35-43.

Politis, D. N. (2003). The impact of bootstrap methods on time series analysis. Statistical Science, 18(2), 219-230.

Shkolnikov, V. M., Andreev, E. M., Jdanov, D. A., Jasilionis, D., Kravdal, Ø., Vågerö, D., \& Valkonen, T. (2011). Increasing absolute mortality disparities by education in Finland, Norway and Sweden, 1971-2000. Journal of Epidemiology and Community Health, 66(4), 372-378. doi:10.1136/jech.2009. 104786.

Siermann, C., Van Teeffelen, P., \& Urlings, L. (2004). Equivalentiefactoren 1995-2000: Methode en belangrijkste uitkomsten. Statistics Netherlands, Sociaal-economische trends, 3, 63-66.

Steingrímsdóttir, Ó. A., Næss, Ø., Moe, J. O., Grøholt, E. K., Thelle, D. S., Strand, B. H., et al. (2012). Trends in life expectancy by education in Norway 1961-2009. European Journal of Epidemiology, 27(3), 163-171.

Stronks, K., van de Mheen, H., Van Den Bos, J., \& Mackenbach, J. P. (1997). The interrelationship between income, health and employment status. International Journal of Epidemiology, 26(3), 592-600. 
Werblow, A., Felder, S., \& Zweifel, P. (2007). Population ageing and health care expenditures: A school of 'Red Herrings'? Health Economics, 16(10), 1109-1126.

Wong, A., Boshuizen, H. C., Polder, J. J., \& Ferreira, J. A. (2015). Assessing the inequality of lifetime health care expenditures: A nearest neighbor resampling approach. Journal of Royal Statistical Society Series A: Statistics in Society (accepted for publication).

Wouterse, B., Huisman, M., Meijboom, B. R., Deeg, D. J., \& Polder, J. J. (2013). Modeling the relationship between health and health care expenditures using a latent Markov model. Journal of Health Economics, 32(2), 423-439.

Yakowitz, S. (1993). Nearest neighbor regression estimation for null-recurrent Markov time series. Stochastic Processes and their Applications, 48(2), 311-318. 